\title{
Current status on the use of recycled aggregates in concrete: Where do we go from here?
}

\author{
Jorge de Brito $^{1^{*}}$, Rui V. Silva ${ }^{1}$ \\ ${ }^{1}$ CERIS-ICIST, DECivil, Instituto Superior Técnico, Universidade de Lisboa, Av. Rovisco Pais, 1049-001 Lisbon, Portugal
}

Received: 05 December 2015 / Accepted: 05 March 2016 / Published online: 17 March 2016

(C) The Author(s) 2016. This article is published with open access.

\begin{abstract}
The consumption of energy and natural resources has been growing exponentially with the significant increase of the economic and industrial activities of the semi-developed nations, becoming one of the major environmental concerns in our time. Several sectors are already pursuing cost-effective solutions to the problem of dumping waste, by reducing their production and adding value to them through their reuse or recycling them into new products, in view of a circular economy. Here, the current state of the recycled aggregates' application in the concrete industry is briefly reviewed, with a particular focus on the existing obstacles to their widespread use and lacking knowledge in general areas, which need to be further researched.
\end{abstract}

Keywords: Concrete; Construction and Demolition Waste; Recycled Aggregates; Sustainability

\section{Introduction}

Concrete is the World's second most consumed material after water. The widespread use of this material is the basis of the present urban development and twice as much concrete is used in construction as the total of all the other building materials combined [1]. Still, despite its importance, one must also recognize its high environmental impacts. The amount of carbon dioxide $\left(\mathrm{CO}_{2}\right)$ emitted to the atmosphere from the cement industry accounts for around $5 \%$ of the global $\mathrm{CO}_{2}$ emissions. In 2006, studies [2] on the projected worldwide production of cement showed that, respectively for a low and a high demand scenario, the estimated production by 2015 would be between 3.6 and 3.8 billion tonnes, and by 2050 from 3.9 to 4.7 billion tonnes (Figure 1). However, in 2014, the European Cement Association [3] estimated that the global production of cement, in that year, was 4.3 billion tonnes, well above the initial projections.

Owing to increasing concerns regarding climate change mitigation, the cement industry's challenge is to reduce its $\mathrm{CO}_{2}$ emissions. Since cement is the primary component in concrete, it is vital to seek new alternatives that reduce this material's carbon footprint. Consequently, apart from alternative cementitious binders with lower energy demands and $\mathrm{CO}_{2}$ emissions, other approaches are being developed to: improve energy efficiency of clinker calcination [4]; use alternative fuels and/or raw materials [5]; promote grinding efficiency [6] and; develop cement-based technology systems in carbon capture and storage [7].

In 2012, the global market for construction aggregates was expected to increase $5.2 \%$ per year until 2015 , up to 48.3 billion tonnes, and is expected to expand even further to 66.3 billion tonnes by 2022 [8]. In 2012, the global construction aggregate market was valued at over $€ 75$ billion [9]. The largest regional market in the world belonged to the Asia-Pacific region, with $42.5 \%$. Europe and North America were the second $(26.9 \%)$ and third $(20.8 \%)$ largest regional markets, respectively. Growing economies in the Asia-Pacific region, namely China, India and Indonesia, are expected to reduce the market shares of Western regions. This is due to the rapid development of infrastructures and other construction markets, which increases the demand for aggregates. Although at a somewhat slower pace, Central and South America, Eastern Europe and some regions in Africa are also expected to increase construction aggregate consumption. Overall, it can be said that both the aggregate market and the cement industry are enormous worldwide and with severe impacts on the environment. Simultaneously, according to Eurostat [10], the total amount of waste generated in the European Union in 2012 was over 2.5 billion tonnes, $34 \%$ of which belonged to construction and demolition activities. In the USA, the Environmental Protection Agency [11] estimated that the generation of debris, from construction, demolition, and renovation of residential and non-residential buildings in 2003, was close to 170 million tonnes.

In 2006 it was estimated that the construction and demolition waste (CDW) produced in China was 120 million tonnes [12].

Although many countries have gone to great lengths to treat high amounts of CDW in recycling plants and reintroduce them into the construction life cycle, many nations still embrace landfilling as the main solution to 
dispose of these materials, thereby leading to other environmental concerns, such as leaching. Barbudo et al. [13] carried out a comprehensive analysis of the amount of leached heavy metals and sulfates from several aggregates from different $\mathrm{CDW}$ recycling plants, with varying concrete, ceramic and asphalt contents, and also of recycled aggregates (RA) with controlled amount of gypsum. According to the limits imposed by the EU Landfill Directive, the leached amounts of heavy metals and sulfates suggest that these materials can be considered as inert or non-hazardous. However, given the fact that some of the values were borderline in terms of having an effect on living organisms according to the ECOTOX Database [14], and because there is a risk of accumulation of these hazardous elements over time, some landfill soils may exhibit high levels of toxicity.

Bearing these factors in mind, the use of RA as a replacement for natural aggregates (NA) in construction applications (e.g. unbound and cement-treated layers, road pavements, mortar, concrete) can be considered one of the most effective approaches for recycling treated CDW and answer many of the problems resulting from the relentless extraction of natural resources and ongoing construction and demolition activities.

\section{Existing barriers to the use of RA in concrete}

In spite of the proven technical feasibility of using RA in structural concrete, various barriers have been identified that prevent the wider production of these construction materials. However, merely identifying and stating these barriers, with an attempt to come up with a logical solution is not equivalent to surpassing them. In fact, although the reincorporation of treated $\mathrm{CDW}$ is perfectly logical for standard practice in construction, many of the identified barriers still remain mostly due to economic reasons. Many countries still commercialize NA at remarkably cheap prices because proper taxation that accounts for their extraction's environmental impact is not applied and the CDW gate fee in recycling plants is not appealing enough to discourage illegal dumping.

Clients and contractors normally claim a lack of confidence on the technical feasibility of using RA in concrete. Similarly to what happens in many other scientific fields, lack of trust is normally accompanied by lack of enlightenment. The use of RA in the production of structural concrete has been extensively studied and is looked upon as a realistic alternative to NA, assuming that the materials are of known high quality $[15,16]$. Indeed, experience has shown that one of the main arguments for not using RA is the high variability of their characteristics. Several recycling plants are either unaware of the most appropriate procedures to obtain RA with the best possible quality, or are simply not motivated to produce RA with good enough quality for high-grade applications. In either case, the quality of the final product may vary on a daily basis or not be good enough for use in structural concrete thereby establishing another effective barrier. Furthermore, some still think that the ecologic footprint of processing CDW into RA is greater than that of NA. Although this may be true in cases where thermal processing stages are applied alongside mechanical methods in an attempt to reduce the adhered mortar content from recycled concrete aggregates, when processed using similar mechanical procedures to those of conventional aggregates, RA exhibit much lower environmental impact [17].

Even though some existing standards and specifications [1820] allow the use of RA in concrete production, most either have very restricting limitations or convey a vague concept of the potential behaviour of RAC. In fact, the main codes $[21,22]$ for design of structural concrete do not contain any clause that can help understand the structural behaviour of a RAC element [23]. Since designers and concrete producers follow these codes in a strict manner, their modification is vital so that they may understand the implications of using RA on the performance of concrete and thus allow a greater use of processed CDW.

The economic and environmental benefits of using RA, as a sustainable alternative to NA, are largely influenced by transportation costs [17]. Indeed, depending on the location of construction and demolition sites relative to the recycling plant, road haulage distances may greatly increase the ecologic footprint and cost of RA, thereby reducing their attractiveness to contractors and concrete manufacturers. Nevertheless, depending on the target application and availability of raw materials on-site, it is possible to use mobile recycling plants and practically eliminate road haulage operations.

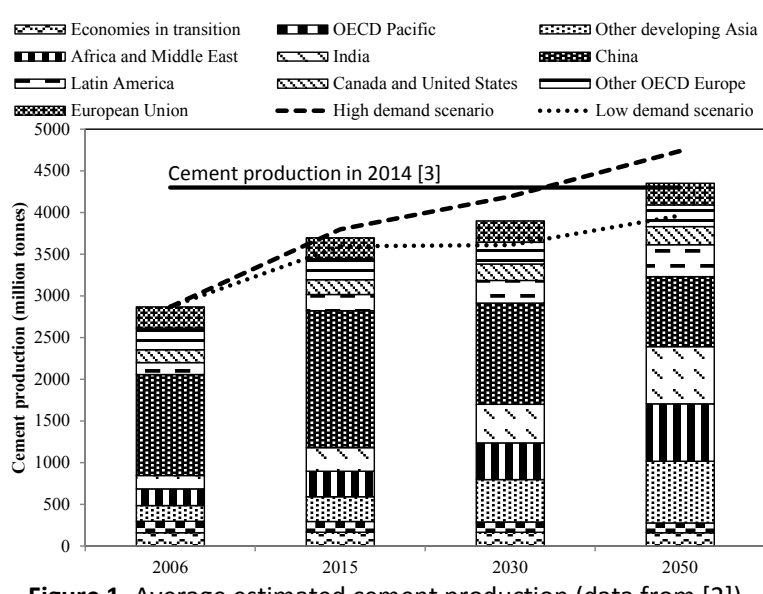

Figure 1. Average estimated cement production (data from [2]).

\section{How can existing standards change to allow the use of RA aggregates in concrete?}

As mentioned above, despite the existence of specifications that allow the use of RA, many of them are out of date and are not sufficiently comprehensive to instil enough confidence in the industry's key actors [23]. In an attempt to overcome this, there have been several recent efforts with the purpose of "building a bridge" between the current state of knowledge on the properties of RAC and its structural 
behaviour. Assuming that there are already sufficient incentives to vanquish aforementioned barriers, designers will require a performance-based approach, which allows adjusting the way RA are incorporated to widely varying circumstances.

One of the main issues thus far in using RA in concrete has been the production of a material with a predictable performance. In a previous study [24], the authors developed a performance-based classification that provides a means to measure the quality of RA based on their physical properties (Table 1). Using this classification, strong correlations were found between the quality of RA and the strength of the resulting concrete $[25,26]$ thereby allowing designers to easily predict the compressive strength of RAC. Furthermore, practical and conservative approaches were also proposed to estimate the moduli of elasticity of RAC, by simply applying a correction factor in the formula, which explains the relationship between this property and the compressive strength of concrete, proposed in existing codes for structural concrete [27]. Furthermore, extensive statistical analyses have allowed the authors to properly map the potential deformation by creep and shrinkage of $\operatorname{RAC}[28,29]$ and also their increased carbonation and chloride ion penetration $[30,31]$. Using the strongly supported evidence from these statistically significant metaanalyses, it became possible to calculate the behaviour of a structural RAC element, with similar load bearing capacity, mid-span deflection and service life as those of a corresponding natural aggregate concrete (NAC), just by making slight adjustments to the cross section's geometry.

Naturally, not only do standards related to the use of RA in concrete production need to change, but specifications associated to construction and demolition activities and processing of the resulting material need to change as well. The performance of the resulting construction material depends on the quality control applied to all life cycle stages of RA (Figure 2).

\section{Recommendations for further research}

In spite of the great number of studies on the subject and of the proven technical feasibility of the material, until further field trials are carried out, RA should be limited to structural applications where research has already been carried out with successful results. Naturally, the quality of the RA used should always be assessed on a case-by-case basis taking into account the end-use application (i.e. low-quality RA for low-grade applications and high-quality RA for high-grade applications).

Several areas have been identified which still need to be further addressed before a wider use of these materials in more demanding structural applications, namely:

- Increase quality control throughout the construction and demolition life cycle

In spite of the technical viability of measuring and predicting how the quality of RA may affect the performance of concrete, as demonstrated in recent developments [24], it is vital to come up with additional measures that can minimize the level of contamination in the final product. The production of high-quality and fit-for-purpose RA, which are easily certifiable according to a specific set of requirements, will boost stakeholders' confidence and increase the demand of a technically viable and potentially more economical alternative to their natural counterparts;

- Life cycle assessment (LCA) and life cycle costs (LCC) analyses of the use of RA and NA in concrete production

Preliminary LCAs showed the environmental impacts are extremely sensitive to road haulage distances [32, 33]. Although it is logical to assume that this may be a determining factor in a LCC, one must also consider the high costs associated to selective demolition and determine how these could affect the global cost of a cubic meter of concrete under several circumstances (i.e. taking into consideration the currently practiced fees and how the creation of natural aggregate taxes would influence the results) [32, 33];

\section{- Time dependent deformation of RAC}

Although the deformation by shrinkage has been scrutinised in several studies, creep of RAC is still not studied in depth, which constitutes a serious impediment to the use of RA in more demanding applications, bearing in mind the much greater deformations expected. Even though the deformation by creep can be calculated using existing prediction models [28], simpler and more precise correction factors need to be developed in order to facilitate their integration in current codes;

Table 1. Physical property requirements of the performance-based classification (adapted from Silva et al. [24]).

\begin{tabular}{|c|c|c|c|c|c|c|c|c|c|c|}
\hline \multirow{2}{*}{ Aggregate class } & \multicolumn{3}{|c|}{ A } & \multicolumn{3}{|c|}{$\mathrm{B}$} & \multicolumn{3}{|c|}{$\mathrm{C}$} & \multirow{2}{*}{$\mathrm{D}$} \\
\hline & I & II & III & I & II & III & 1 & II & III & \\
\hline Minimum oven-dried density $\left(\mathrm{kg} / \mathrm{m}^{3}\right)$ & 2600 & 2500 & 2400 & 2300 & 2200 & 2100 & 2000 & 1900 & 1800 & \multirow{3}{*}{$\begin{array}{l}\text { No } \\
\text { limit }\end{array}$} \\
\hline Maximum water absorption (\%) & 1.5 & 2.5 & 3.5 & 5 & 6.5 & 8.5 & 10.5 & 13 & 15 & \\
\hline Maximum LA abrasion mass loss (\%) & \multicolumn{3}{|c|}{40} & \multicolumn{3}{|c|}{45} & \multicolumn{3}{|c|}{50} & \\
\hline
\end{tabular}




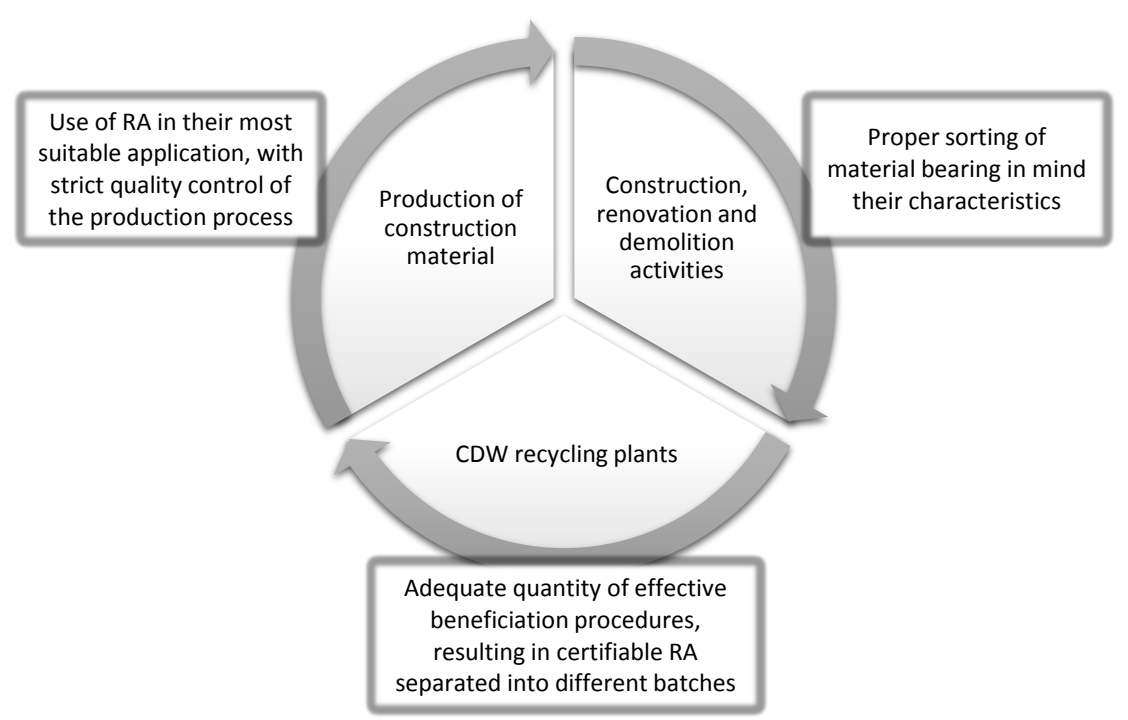

Figure 2. Life-cycle of recycled aggregates.

\section{- Structural behaviour}

In view of the feasibility of using RA in concrete, some have taken the step forward of analysing its effect on the material's macro-structural behaviour. Generally, it has been observed that reinforced RAC exhibits similar failure mechanisms to those of a corresponding NAC element, whereas any potential slight decrease in structural performance can be correlated to the decline in the material's mechanical behaviour [34, 35]. Also, even though structural RAC may exhibit similar load bearing capacity, it is quite probable that the recycled elements will exhibit a greater deflection [36]. Before a wider use of RA in more demanding structural applications, there are several areas of interest, which still need to be further studied, in order to bring about the necessary modifications in structural codes to account for this differing behaviour, namely long-term deflection, shear strength, fatigue, punching shear, load redistribution, and prestressed concrete;

\section{- Meso and microstructure of RAC}

The results of one of the few studies on the mesostructure of RAC [37] showed that, by means of a finite element analysis, after loading, failure begins in the old interfacial transition zone (ITZ), followed by fracture in the new ITZ, which develops into a crack along the old adhered mortar. Bearing in mind the fragility in this zone, further studies in these areas are required to mitigate the strength loss when incorporating RA.

Some of these aspects are within the scope of the recently appointed RILEM technical committee for recycled aggregate concrete (TC RAC), who will work in collaboration with fib in several research areas of interest that will include, but not be limited to:

- RAC mix design;

- Influence of different sources of RA on RAC;

- Properties of fresh and early-age RAC and their predictions;

- Stress-strain relationship of RAC;
- Performance under restraints by steel and FRP tubes or bars;

- Component structural behaviour (moment, shear, punching);

- Case-studies in structural applications of RAC;

- Fire-resistant performance and fire design of RAC structures.

\section{Conclusions}

The general concern of adding value to processed construction and demolition waste is a complex issue, which needs to be tackled on several fronts. One of the most effective ways of stimulating proactive engagement by construction and demolition industries is to present RA as an economically appealing and technically viable alternative to $\mathrm{NA}$, prompted by the introduction of levies and landfill taxation of inappropriately separated CDW upon delivery to recycling plants, assuming that there is a strict control over illegal dumping operations. Thereon, substantial improvements will be observed both in the methodology applied during demolition with significantly less amounts of waste dumped in landfills as well as the selection of a more sustainable alternative to their natural counterparts upon purchase, thereby contributing to a fully closed loop in the circular economy.

Manufacturing operations of CDW recycling plants must adapt to the material's characteristics and its end use application. In circumstances where comprehensive beneficiation procedures would be applied to CDW, the resulting material can then be sorted into several batches depending on the RA's physical properties, rather than based solely on their composition. This allows the production of a wide range of materials with known quality that can be used in a broadened scope of applications. With this in mind, the proposed performance-based classification of RA, besides representing a practical approach, in terms of its easy adaptability and application 
by all professionals in the construction industry, has also been shown to be strongly correlatable to the performance of the resulting concrete materials.

The properties of concrete are fundamentally dependent on those of the aggregates used. This happens in both NAC and RAC. Upon strict quality control of CDW beneficiation, followed by certification, the variability of RAs' characteristics will be minimized thereby allowing the production of materials with known quality. In previous research, the behaviour of RAC, containing various types of RA of known quality, was mapped out and translated into several formulae and methods that are easily adaptable to existing structural codes. Applying the proposed conservative and highly flexible methods can allow using these materials with a high level of confidence and in a way that can be adjusted to several variables present in real concrete structures.

Still, despite the technical feasibility of incorporating RA in concrete using the proposed methods, there are several general areas that still need to be explored in depth before using a greater amount of these materials in more demanding applications. Bearing this in mind, it is vital that further research is made on the identified areas in order to facilitate the wider use of recycled aggregates in the production of concrete, thereby contributing to a greater sustainability in the construction industry.

\section{Acknowledgements}

The authors are grateful for the support of the CERIS-ICIST Research Institute, IST, University of Lisbon and FCT (Foundation for Science and Technology).

\section{References}

[1] CCANZ, Best practice guide for the use of recycled aggregates in new concrete. CCANZ Publications: Cement and Concrete Association of New Zealand, 2011.

[2] IEA, Cement Roadmap. 2009.

[3] CEMBUREAU, World Cement Production 2014 by region and main countries. 2014

[4] Q. Yin, Q. Chen, W.-J. Du, X.-L. Ji, L. Cheng, Design requirements and performance optimization of waste heat recovery systems for rotary kilns. Int J Heat Mass Transfer (2016) 93: 1-8.

[5] S.P. Deolalkar, Chapter 3 - Feasibility of Using Alternative Fuels in Cement Kilns. In: S.P. Deolalkar, editor. Designing Green Cement Plants: Butterworth-Heinemann, 2016.

[6] T.S. Sverak, C.G.J. Baker, O. Kozdas, Efficiency of grinding stabilizers in cement clinker processing. Miner Eng (2013) 43-44: 52-57.

[7] D.P. Siriwardena, S. Peethamparan, Quantification of $\mathrm{CO} 2$ sequestration capacity and carbonation rate of alkaline industrial byproducts. Constr Build Mater (2015) 91: 216-224.

[8] Freedonia, World construction aggregates. Industry Study No 2838. Cleveland, Ohio, USA: The Freedonia Group, 2012.

[9] Timetric, Global Construction Aggregates Market - Key Trends and Opportunities to 2017. Timetric, 2013.

[10] Eurostat, Waste statistics in Europe. 2015.

[11] EPA, United States Environmental Protection Agency. 2014.

[12] W. Zhao, S. Rotter, The current situation of construction \& demolition waste management in China. 2nd International Conference on Bioinformatics and Biomedical Engineering, ICBBE 2008. Shanghai: IEEE Computer Society, 2008.
[13] A. Barbudo, A.P. Galvín, F. Agrela, J. Ayuso, J.R. Jiménez, Correlation analysis between sulphate content and leaching of sulphates in recycled aggregates from construction and demolition wastes. Waste Manage (Oxford) (2012) 32: 1229-1235.

[14] EPA, ECOTOX Database. 2015.

[15] S. Nagataki, A. Gokce, T. Saeki, M. Hisada, Assessment of recycling process induced damage sensitivity of recycled concrete aggregates. Cem Concr Res (2004) 34: 965-971.

[16] D. Pedro, J. de Brito, L. Evangelista, Influence of the use of recycled concrete aggregates from different sources on structural concrete. Constr Build Mater (2014) 71: 141-151.

[17] A.M. Braga, Comparative analysis of the life cycle assessment of conventional and recycled aggregate concrete Instituto Superior Técnico, University of Lisbon, Portugal, 2015.

[18] BRE, Recycled aggregates. BRE Digest 433, Cl/SfB p(T6). Watford, UK: Building Research Establishment, 1998.

[19] RILEM, Specifications for concrete with recycled aggregates. Mater Struct (1994) 27: 557-559.

[20] NEN-5905. Dutch supplement to NEN-EN 12620+A1 Aggregates for concrete. 2010, 3 p. 2010.

[21] EN-1992-1-1, Eurocode 2 - Design of concrete structures: Part 1-1: General rules and rules for buildings. Brussels, Belgium: Comité Européen de Normalisation (CEN), 2008.

[22] ACl-318, Building code requirements for structural concrete $(\mathrm{ACl}$ 318-14) and commentary. Farmington Hills, Michigan, USA: American Concrete Institute - ACl Committee 318, 2014.

[23] P. Goncalves, J. de Brito, Recycled aggregate concrete (RAC) - comparative analysis of existing specifications. Mag Concr Res (2010) 62: 339-346.

[24] R.V. Silva, J. de Brito, R.K. Dhir, Properties and composition of recycled aggregates from construction and demolition waste suitable for concrete production. Constr Build Mater (2014) 65: 201-217.

[25] R.V. Silva, J. de Brito, R.K. Dhir, The influence of the use of recycled aggregates on the compressive strength of concrete: a review. Eur J Env Civ Eng (2014) 19: 825-849.

[26] R.V. Silva, J. de Brito, R.K. Dhir, Tensile strength behaviour of recycled aggregate concrete. Constr Build Mater (2015) 83: 108-118.

[27] R.V. Silva, J. de Brito, R.K. Dhir, Establishing a relationship between the modulus of elasticity and compressive strength of recycled aggregate concrete. J Cleaner Prod (in press) DOI: 101016/jjclepro201510064 (2015).

[28] R.V. Silva, J. de Brito, R.K. Dhir, Comparative analysis of existing prediction models on the creep behaviour of recycled aggregate concrete. Eng Struct (2015) 100: 31-42.

[29] R.V. Silva, J. de Brito, R.K. Dhir, Prediction of the shrinkage behavior of recycled aggregate concrete: A review. Constr Build Mater (2015) 77: 327-339.

[30] R.V. Silva, J. de Brito, R. Neves, R. Dhir, Prediction of chloride ion penetration of recycled aggregate concrete. Mater Res (2015) 18: 427-440.

[31] R.V. Silva, R. Neves, J. de Brito, R.K. Dhir, Carbonation behaviour of recycled aggregate concrete. Cem Concr Compos (2015) 62: 22-32.

[32] A. Coelho, J. de Brito, Economic viability analysis of a construction and demolition waste recycling plant in Portugal - part II: economic sensitivity analysis. J Cleaner Prod (2013) 39: 329-337.

[33] A. Coelho, J. de Brito, Economic viability analysis of a construction and demolition waste recycling plant in Portugal - part I: location, materials, technology and economic analysis. J Cleaner Prod (2013) 39: 338-352.

[34] M. Arezoumandi, A. Smith, J.S. Volz, K.H. Khayat, An experimental study on shear strength of reinforced concrete beams with $100 \%$ recycled concrete aggregate. Constr Build Mater (2014) 53: 612-620.

[35] Y. Wang, J. Chen, Y. Geng, Testing and analysis of axially loaded normal-strength recycled aggregate concrete filled steel tubular stub columns. Eng Struct (2015) 86: 192-212.

[36] A.B. Ajdukiewicz, A.T. Kliszczewicz, Comparative tests of beams and columns made of recycled aggregate concrete and natural aggregate concrete. J Adv Concr Technol (2007) 5: 259-273.

[37] H.F. Yang, Z.H. Deng, Y.F. Hu, Microstructure and Finite Element Analysis of Recycled Aggregate Concrete. Applied Mechanics and Materials (2013) 357: 1383-1388. 